University of South Florida

DIGITAL COMMONS

Digital Commons @ University of

@ UNIVERSITY OF SOUTH FLORIDA

South Florida

USF Tampa Graduate Theses and Dissertations

USF Graduate Theses and Dissertations

$7-1-2014$

\title{
Using Video Modeling and Video Feedback to Improve Olympic Weightlifting Technique
}

Danah Mulqueen

University of South Florida, danah.mulqueen@gmail.com

Follow this and additional works at: https://digitalcommons.usf.edu/etd

Part of the Behavioral Disciplines and Activities Commons

\section{Scholar Commons Citation}

Mulqueen, Danah, "Using Video Modeling and Video Feedback to Improve Olympic Weightlifting Technique" (2014). USF Tampa Graduate Theses and Dissertations.

https://digitalcommons.usf.edu/etd/5280

This Thesis is brought to you for free and open access by the USF Graduate Theses and Dissertations at Digital Commons @ University of South Florida. It has been accepted for inclusion in USF Tampa Graduate Theses and Dissertations by an authorized administrator of Digital Commons @ University of South Florida. For more information, please contact digitalcommons@usf.edu. 
Using Video Modeling and Video Feedback to Improve Olympic Weightlifting Technique

by

Danah Mulqueen

\author{
A thesis submitted in partial fulfillment \\ of the requirements for the degree of \\ Master of Arts \\ in Applied Behavior Analysis \\ Department of Child and Family Studies \\ College of Behavioral and Community Sciences \\ University of South Florida
}

Co-Major Professor: Kim Crosland, Ph.D.

Co-Major Professor: Raymond G. Miltenberger, Ph.D.

Lisa Witherspoon Ph.D.

Date of Approval:

July 1, 2014

Keywords: Behavioral Coaching, Athletic Performance, Sports, Skill Acquisition

Copyright (C) 2014, Danah Mulqueen 


\section{Table of Contents}

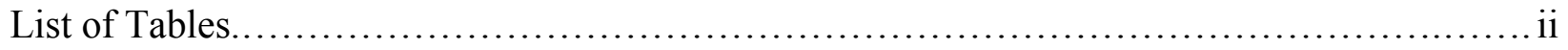

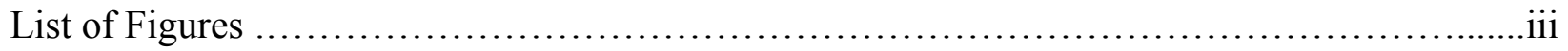

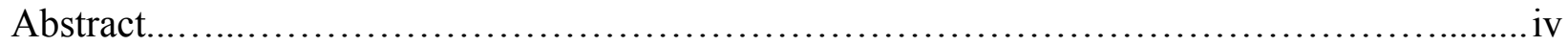

Chapter One: Introduction...................................................... 1

Chapter Two: Method................................................................. 7

Participants and Setting............................................................. 7

Materials.........................................................................

Target Behavior and Data Collection.......................................... 9

Interobserver Agreement....................................................... 10

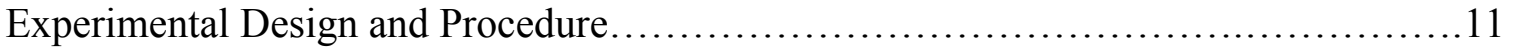

Practice conditions.................................................... 11

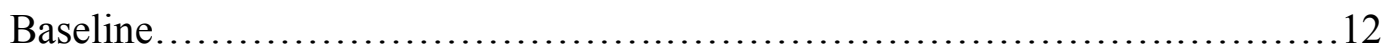

Expert video modeling with video feedback.............................. 14

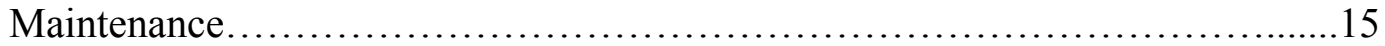

Social Validity Measures................................................... 16

Chapter Three: Results........................................................... 17

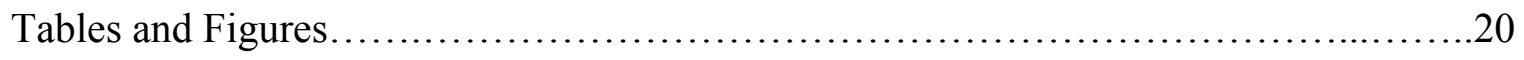

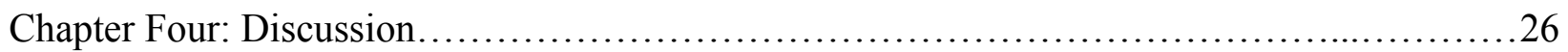

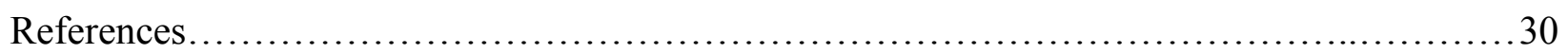

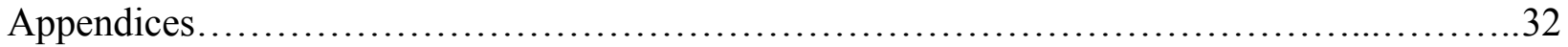

Appendix A: Inclusion Criteria.................................................. 33

Appendix B: Physical Activity Readiness Questionnaire (PAR-Q)...................... 34

Appendix C: Task Analysis/Data Collection Sheet: Clean and Jerk..................... 35

Appendix D: Task Analysis/Data Collection Sheet: Snatch......................... 36

Appendix E: Social Validity Questionnaire................................... 37

Appendix F: IRB Approval Letter ................................................ 39 


\section{List of Tables}

Table 1: Average Scores for Clean and Jerks and Snatches............................. 20

Table 2: Results from Participants' Social Validity Questionnaire...........................21

Table 3: Results from Trainer's Blind Scoring Social Validity.............................22

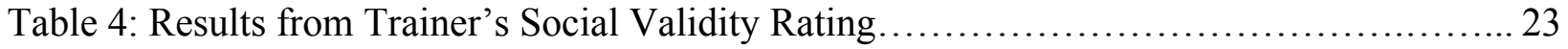




\section{List of Figures}

Figure 1: Percentage of Correct Steps Displayed Across Behaviors.........................24

Figure 2: Percentage of Correct Steps Displayed Across Participants.......................25 


\begin{abstract}
Behavioral coaching procedures have been evaluated and enhanced over the years to find the most effective interventions for athletic performance in a variety of sports settings. Different types of feedback have been evaluated for effectiveness in teaching and improving skills. The purpose of this study was to examine the effects of video modeling and video feedback to improve technique for three novice individuals in a fitness program incorporating Olympic weightlifting. Two weightlifting events, the clean and jerk and snatch, were targeted for intervention. Each lift was broken down into a task analysis, and trainers used the task analysis to score each lift. Video modeling and video feedback was effective in improving all three participant's lifts from baseline. Annie's lifts improved from $37 \%$ in baseline to $79 \%$ in intervention for the clean and jerk, and $24 \%$ to $75 \%$ for the snatch. Rich's lifts improved from $79 \%$ in baseline to $95 \%$ following intervention for clean and jerk, and $58 \%$ to $89 \%$ for the snatch. Fran improved from $60 \%$ to $87 \%$ on the clean and jerk, and from $51 \%$ to $84 \%$ on the snatch. Keywords: video feedback, video modeling, behavioral coaching, sport and fitness, athletic performance, Olympic weightlifting
\end{abstract}




\section{Chapter One:}

\section{Introduction}

A number of behavioral interventions have been assessed for effectiveness in improving athletic skills and sports performance. Researchers have seen success with public posting (McKenzie \& Rushall, 1974), goal setting and performance feedback (Smith \& Ward, 2006), behavioral coaching (Allison \& Ayllon, 1980), and video feedback and video modeling (BenitezSantiago \& Miltenberger, 2011; Boyer, Miltenberger, Bastche, \& Fogel, 2009) when applied in an athletic setting.

Coaching procedures vary greatly across sport settings depending on a number of variables including, but not limited to, number and age of athletes, type of sport, coaching resources, and coach's education and background. Behavioral coaching packages typically employ the use of some combination of behavioral skills training (BST) to include verbal instructions; modeling by a coach, peer or expert; opportunity for practice of the skill; and verbal feedback (Allison \& Ayllon, 1980; Fitterling \& Ayllon, 1983; Kladopolous \& McComas, 2001; Smith \& Ward, 2006; Hazen, Johnstone, Martin \& Srikamenswaran, 1990). Packages may also include other features differing from typical BST such as goal setting (Stokes, Luiselli, Reed, \& Fleming, 2010). Behavioral coaching has been effective with athletes in a variety of sports such as swimming (Hazen et al., 1990), track (Shapiro \& Shapiro, 1985), tennis (Allison \& Ayllon, 1980), football (Allison \& Ayllon, 1980; Stokes et al., 2010) and gymnastics (Allison \& Ayllon, 1980; Wolko, Hrycaiko, \& Martin, 1983). 
While delivery of instructions, modeling, and practice are all necessary components of behavioral skills training and coaching, feedback is a critical feature of learning, in itself, and the method of feedback delivery can directly impact the learning process (Dowrick, 1991). The feedback component of typical behavioral coaching packages more frequently incorporates verbal praise, encouragement, and error correction. This type of feedback is usually minimally effective or ineffective on its own for performance improvements, and researchers have attempted to implement techniques to improve the effectiveness of feedback in a variety of settings (Dowrick, 1991).

An increasingly popular and seemingly widely accepted form of feedback in coaching packages is video feedback. In an early review by Rothstein and Arnold (1974) video feedback had been used as a learning aid in over 50 research studies, and more than $50 \%$ of the studies reviewed showed no significant improvement from baseline to intervention conditions. These results indicate the type of feedback and delivery appears to be important when considering its effectiveness. It was expressively stated by Hazen et al., (1990) that athletes cannot simply be expected to improve based upon casual viewing of errors on a videotape; however, this is frequently the case in a variety of coaching settings.

Dowrick (1991) suggests when using video feedback, coaches should focus on critical elements of performance, minimize delay between performance of the skill and viewing, and that athletes should have control over the video to slow playback and replay when necessary to analyze their own performance during the feedback session. Several studies have employed the use of video feedback as a component of behavioral coaching packages with favorable outcomes.

Stokes et al. (2010) evaluated a coaching treatment package while intending to improve offensive line pass blocking with high school football athletes. The researchers in this study 
systematically implemented descriptive, video and acoustical guidance (TAG) feedback in the process of teaching the targeted athletic skills. TAGteach was implemented for one participant on skill components that were not consistently executed correctly, and was successful in assisting the participant to meet criterion. This study evaluated performance during practice and games, and found the skills targeted in practice transferred to game settings. The researchers also conducted follow-up for the following season and found skill execution decreased most likely due to lack of practice during the off season, but found that skills improved quickly with the reimplementation of combined descriptive and video feedback.

Hazen et al. (1990) compared behavioral coaching to individual versus group video feedback with a youth swim team in which athletes viewed their own video while receiving positive and corrective feedback. The individual video feedback procedure was found to be more effective in improving performance than video feedback in a group. Similarly, Zeigler (1994) was successful in improving attentional shift of soccer players to develop tactical decisions and specific skills using video feedback in settings inclusive and alternative to the practice setting.

Other researchers have evaluated the effectiveness of expert video models combined with video feedback to improve athletic skills. Boyer et al. (2009) implemented the first study to use video feedback on a set of complex athletic skills. This study used an intervention with four young competitive gymnasts on three complex targeted gymnastic skills. In baseline, the gymnasts only received verbal feedback. Intervention used visual feedback by having the gymnasts view a video of an expert model, followed by a video of him or her self performing the skill. The gymnast then watched the two videos side by side with specific points identified in freeze frames, followed by an opportunity for practice. This intervention improved performance 
more quickly than coaching alone; however, the gymnasts infrequently achieved the optimal performance criteria of $80 \%-100 \%$ correct.

Benitez-Santiago and Miltenberger (2011) evaluated the effects of video feedback on performance of complex martial-arts skills. In baseline, participants were taught three different Brazilian martial arts skills using basic behavioral skills training procedures including peer modeling. The participants received intervention after regularly scheduled practices, in which they were videotaped executing the targeted skills, and were able to view the skills following each attempt at the skill. They were provided with positive and corrective feedback while viewing the video, and were able to use the slow motion, replay and pause controls on the video. Exposure to intervention in this study increased skill performance more rapidly than in regular practice. Similarly to the Boyer et al. (2009) study, performance criteria of $80-100 \%$ mastery of the skill taught was still an infrequent event with this intervention. This limitation could be due to the level of complexity of the skills being evaluated in both of these studies.

As discussed, video feedback has been used as an effective component of treatment packages to correct simple behaviors such as eye gaze of basketball players (Harle \& Vickers, 2001), and also used as a single intervention to teach highly complex behaviors as seen in gymnastics and Brazilian martial-arts (Benitez-Santiago \& Miltenberger, 2011; Boyer et al., 2009). Though behavioral research in sports has developed over the years, there are still a number of areas that would benefit from future research in the field of sport psychology/behavior and performance improvements. Given the investigative efforts of researchers on the effectiveness and use of video feedback in an athletic arena, there is still a need for further investigation and expansion into a larger variety of sport settings. Video feedback has not been 
systematically evaluated in the context of improving foundational skills in load bearing sports, and no studies currently exist evaluating behavioral coaching in Olympic weightlifting.

Traditional weightlifting and Olympic weightlifting can be categorized as two different types of exercise focuses. Traditional weightlifting typically implies the use of weights as tools to isolate and stress the muscles of the body in order for the muscles to grow. Whereas, Olympic weightlifting is categorized as a functional skill or movement in which the main goal is to lift a heavy weight with perfect technique. Olympic weightlifting lifts are frequently used as strengthening exercises for football or competitive Olympic weightlifting, as well as running and jumping sports. Olympic weightlifting has been a competitive sport for three centuries, mainstreamed to the general public, and increased in popularity over the past decade in the development of fitness programs, such as CrossFit. In 2007 the first official CrossFit Games opened and sparked an explosion of local, regional and national competitive arenas for this sport (Sullivan, www.vpxsports.com).

Olympic weightlifting utilizes explosive movements of the hips to lift heavy amounts of weight from the ground typically to an overhead position. These movements are technically difficult to perform and require the assistance and oversight of a skilled coach or trainer in acquisition to maximize efficiency in the movement and prevent injury due to incorrect form (Folger, 2006). The use of proper technique can greatly reduce the potential for injury in these sports (Stone, Fry, Ritchie, Stoessel-Ross \& Marsit, 1994).

Coaching for Olympic weightlifting frequently involves verbal instructions in combination with modeling of the skill by a trainer. The trainee usually has an opportunity for practice followed by some form of corrective feedback from the trainer. This process may be completed several times until the individual has acquired some or most of the skill necessary to 
effectively lift the weight. The principles of Olympic lifting are consistent across settings; however, as seen in many other sports, coaching components and styles vary greatly.

With an increasing competitive arena, the functional and foundational movements of Olympic weightlifting warrant empirical evaluation for effective coaching and skill acquisition for the benefit of the athlete. Given the successful implementation of video modeling and video feedback in other sports, in addition to a need for interventions that improve foundational skills to promote optimal performance and safety, this study will extend the use of video technology to weightlifting. This study attempted to extend the use of video technology as a behavioral coaching tool to improve proper technique in Olympic weightlifting more rapidly than typical coaching methods. 


\section{Chapter Two:}

\section{Method}

\section{Participants and Setting}

Annie, Rich, and Fran were three healthy adults participating in a fitness program involving an Olympic weightlifting component. Each of the three participants had less than one year of experience in the fitness program and fell within the ages of 30 to 39 years old. Annie was new to the program and had only 2 weeks experience upon entering the study. Rich had 11 months of experience, and Fran had been participating in the program for 3 months. All three of the participants were identified by trainers at a CrossFit gym as candidates for the study to improve their lifting form. Once each participant was identified, the trainer distributed a flier with information about the study and asked the potential participant to contact the primary researcher for more information if he or she was interested.

Once each participant contacted the researcher and expressed interest in the study, he or she received the inclusion criteria form (Appendix A) and informed consent to participate in the study. The principal investigator reviewed both forms, explained procedures used in the study, as well as, the risks and benefits of participating. Each participant had the opportunity to ask questions about the study and given one week to provide a decision about his or her participation after receiving the inclusion criteria and informed consent for review. Once each participant signed informed consent to participate in the study, he or she was asked to fill out the PAR-Q pre-screening questionnaire to ensure he or she was at minimal health risk to participate 
(Appendix B). If the participant answered yes to any of the PAR-Q questions he or she would be excluded from the study. No participants were excluded from the study for health related reasons.

Each of the participants individually completed basic fundamentals sessions with a certified trainer prior to participating in the study as part of the inclusion criteria. Each participant completed these upon becoming a member of the program where the study was carried out. These sessions are necessary for new members to complete in order to learn the basic movements used in the majority of workouts, and also to learn how to safely terminate a lift when the lift is either being performed incorrectly or when the weight is too heavy and the athlete can not follow through with the lift any further, to minimize potential injury. The head trainer at the CrossFit program attested that each participant completed these sessions.

The study was conducted in a CrossFit gym, where the participants typically train. The gym consisted of matted flooring and equipment necessary to complete Olympic lifts. The setting also included equipment used for metabolic conditioning and gymnastic components of CrossFit, including but not limited to pull up bars, row machines, ropes, tires, kettle bells, plyometric boxes, medicine balls, etc. Metabolic conditioning and gymnastic components of CrossFit are discussed in the methods section of this paper to further describe practice conditions. Neither of these components was explored in this study.

\section{Materials}

Materials included an Apple ${ }^{\mathrm{TM}} \mathrm{iPad}$ with camera used to video record the participants performing the target skills. The Coach's Eye $C$ application for iPad, was used to provide video feedback. This application is designed for sports video analysis, and was used to conduct sideby-side comparison between the participant's performance videos and a video model. The 
application has instant camera access, and contains easily accessible pause and slow motion controls.

Other materials included were equipment necessary to complete each target lift for the study, including rubber weighted plates at 5, 10, 25, and 35lb increments, novice and standard barbells of 15 and 45lbs, and barbell cuffs necessary for securing plates on barbells while completing lifts.

\section{Target Behaviors and Data Collection}

The target behaviors assessed were two fundamental Olympic lifts termed; clean and jerk, and snatch. These two types of lifts are primary events performed in the Olympics as well as national and regional Olympic weightlifting and CrossFit competitions. The Clean and Jerk for the purposes of this study is defined as a lift in which a weight is raised from the floor and received at shoulder height, followed by standing and rapidly pushing the weight overhead in an explosive movement accompanied by a split lunge of the legs. The Snatch is defined as lifting a barbell from the floor to an overhead position with arms locked overhead using a smooth continuous movement. A task analysis operationally defining each component of the two lifts is located in Appendices C and D. The task analyses were created based on widely trained technique. Five certified trainers at the gym where the study was conducted reviewed, amended, and agreed upon the task analysis prior to its use for this study.

The task analysis was used for each lift to score whether or not a component of the lift was correctly executed. The components were scored as a yes $(+)$ or no (-) based on correct or incorrect execution. The score of each lift was calculated as a percent correct by counting the number of correct steps in each trial divided by the total number of steps for the specific target behavior, multiplied by 100 . 
Trainers assisting with this study held a minimum of CrossFit level one certification. This certification certifies the trainer has attended and passed a class on instruction for training CrossFit, including basic Olympic lifting such as the lifts targeted for this study. The trainers assisting with the study were trained on scoring the task analysis by first reviewing the task analysis for each lift, then viewing pre-selected videos of each of the target lifts and scoring the lifts using the task analysis. The trainers scored training videos until 100\% scoring reliability was achieved for at least two videos of each lift (4 total videos).

\section{Interobserver Agreement}

Interobserver agreement (IOA) was collected based on scoring the task analysis for the two types of lifts. Trainers assisting with the study reviewed the videos of the participant's performance and marked (+) for the occurrence of a correct component step and (-) for the absence or error of the target behavior on the task analysis scoring sheet.

Percent agreement was calculated by dividing the number of agreements (in which both observers recorded + or both recorded -) on all steps of the task analysis by the total number of steps then multiplied by 100 . IOA was collected for Annie during $39.7 \%$ of her total lifts across all phases. Average agreement in baseline for the clean and jerk was $81 \%$ and for the snatch was $78 \%$. Average agreement for intervention on clean and jerk was $81 \%$ and $83 \%$ for intervention on snatch. In maintenance, agreement was $86 \%$ for clean and jerks, and $83 \%$ for snatches. IOA overall average for all of Annie's lifts was $81 \%$ (range $72 \%-86 \%$ ) for snatches, and $83 \%$ (range $76 \%-86 \%$ ) for clean and jerks. For Rich, IOA was collected on $46 \%$, and for Fran, on $40 \%$ of all lifts across phases. The average agreement for Rich's baseline lifts was $90 \%$ for clean and jerk and $91 \%$ for snatch. IOA for Rich's intervention lifts averaged $91 \%$ for clean and jerk and $94 \%$ for snatch. In maintenance, agreement was $100 \%$ for clean and jerks, and $94 \%$ for snatches. 
Average agreement for Fran's baseline lifts was 87\% for clean and jerk and 90\% for snatch. Average IOA for Fran's intervention lifts were $90 \%$ for clean and jerk and $89 \%$ for snatch. In maintenance, agreement was $90 \%$ for clean and jerks, and $83 \%$ for snatches. Overall average for Rich's lifts was 95\% (range 86\% - 100\%) for clean and jerks, and 95\% (range 83\% - 100\%) for snatches. Average IOA for Fran's lifts was $89 \%$ (range $83 \%$ - 100\%) for clean and jerks, and $83 \%$ for snatches (range $78 \%-100 \%$ ).

\section{Experimental Design and Procedure}

A multiple baseline across behaviors and participants was used to evaluate the effects of video modeling and video feedback on improving Olympic lifting technique for the two lifts for each participant.

Practice conditions. CrossFit is comprised of three main areas of exercise, which are metabolic conditioning, gymnastics, and Olympic weight lifting. Metabolic conditioning uses exercises targeted to increase heart rate and increase VO2 max capacity to improve cardio performance. These exercises include running, rowing, and performing other exercises at a fast pace. Gymnastics for the purposes of CrossFit involves exercises such as pull-ups, handstands, and muscle-ups, among others to improve core balance and muscle strength. Olympic weightlifting employs the use of explosive movement of the hips to lift weights, which may otherwise be too heavy to lift from the ground to overhead with only the use of primary muscle groups (as described previously).

At the site used for this study, practice conditions consisted of written instructions on a white board for skills to be completed during the time allotted for practice, followed by a brief explanation and clarification by the head trainer. 
Typical practices were split into three primary sections, most often including a $15 \mathrm{~min}$ "warm up" to loosen muscles and prepare the body for further training, 15 minutes of "skills training" in which one or two target skills were selected and the participant worked on only those specific skills, and, finally, 30 minutes of an intensive "workout of the day" (WOD) that involved a combination of metabolic conditioning, Olympic lifting and gymnastics components. Participants usually performed the skills at their own pace in a setting of up to 15 other individuals. Restrictions were not placed on coaches or members to limit or modify typical feedback that the participants received within the natural setting. Throughout the study the participants were subjected to standard practice conditions, which included comments and verbal feedback from trainers and other members consistent with what typically occurred within the gym.

For the purposes of this study, assessments of the target behaviors in all phases occurred during regular scheduled practices, up to 3 times per week for each participant. The assessment sessions took place during the 15 min period designated for "skills training" in which the skill was targeted for focused practice following the standard 15 min warm up period. The assessment sessions lasted about 15 to 20 min each. All lifts in each session were video recorded. Sessions occurred one to three times per week for each participant. In each recording session the participant attempted the targeted lifts three times, and each lift was scored individually.

Baseline. Baseline data was taken for each lift under normal practice conditions. The weight load used during assessment in all phases was determined by calculating $60 \%$ to $65 \%$ of each participant's maximum capacity for one repetition of each lift for Fran and Rich. Annie's weight load remained the same as the weight used in her fundamental sessions with the trainer prior to entering the study due to her limited experience with CrossFit and Olympic weightlifting. 
Maximum load (1 rep max) is typically determined by practicing a lift and gradually increasing the weight on the bar until the individual can no longer finish the lift without dropping the bar. The benefit and purpose of finding 1 rep max is that Olympic weight lifting is not only based on lifting with flawless technique, but also, to lift as much or heavier weight than a potential competitor. In CrossFit programs, there is typically a prescribed $(\mathrm{Rx})$ weight for each workout of the day. Most participants begin well below (scale) the Rx weight and gradually increase toward the prescribed weight as strength and technique improves. Each participant's 1 rep max for each target lift was assessed during an initial evaluation prior to beginning baseline assessment under supervision of a certified trainer. Rich used 95lbs throughout the course of the study for both the clean and jerk, as well as the snatch. Fran used 55lbs for the clean and jerk and $45 \mathrm{lbs}$ for the snatch. Annie used 35lbs for both clean and jerk and snatch, which was the weight used during her fundamental session, and 1 rep max was not assessed due to severe lack of proper technique observed in her fundamentals sessions.

The calculation of $60 \%$ to $65 \%$ of 1 rep max was chosen for the study to allow the participant the opportunity to practice technique with a low enough weight to avoid severe compromise of the skill during training, but still challenging enough to experience the benefits of strength training. Often times, progressions in strength training will begin around $60-65 \%$ of an individual's maximum capacity and gradually build the individual's 1 rep max.

During skills practice, a trainer asked the participant to perform a clean and jerk with the weight determined prior to beginning baseline. The trainer joined the participant on the main floor of the gym as they set up their equipment and performed a clean and jerk, while the researcher video recorded the lifts. Each lift was recorded and the trainer gave verbal feedback to the participant, which was consistent with a typical practice session. This procedure was repeated 
for two more lifts of the clean and jerk. The participant was given up to a 1 min rest period beginning immediately at the end of each lift. The rest period was given to allow the participant to rest his or her muscles prior to the next lift, and simulate the approximate amount of time between lifts in the intervention phases.

The same procedure was repeated for the snatch following a two to five min period for the participant to set up an appropriate bar to complete a snatch, if a change in weight was necessary. Performance was video recorded and each lift was scored based on accuracy of each component step from the task analysis. Trainers could not review the video to provide feedback during baseline; therefore, no feedback was given to the participant based on the video recording during baseline. Upon the completion of the two different sets, the assessment period ended and the participant moved on to the final 30 min section of practice previously described at the "WOD".

Expert video modeling with video feedback. The intervention phase for this study included the simultaneous presentation of an expert video model and video feedback. The expert video model for the study was a video of a professional Olympic weightlifter and CrossFit competitor. Videos of the model were obtained for each of the target lifts (clean and jerk and snatch). The expert videos were used in a side-by-side comparison with the participant's own video recorded performance.

To begin intervention, the participant watched the expert video model performing a clean and jerk next to the participant's last video from baseline performing the clean and jerk prior to completing the first intervention lift. Once the participant viewed the two videos together, the trainer asked the participant to perform a clean and jerk with the weight percentage determined in baseline. The participant performed the skill while the researcher recorded the performance. 
Following performance of the skill, the researcher and trainer showed the participant their performance next to the video model on an Apple iPad ${ }^{\mathrm{TM}}$ and allowed the participant to review the video of him or herself in a side by side comparison using the pause, fast forward, replay and slow motion controls. The participant received verbal positive and corrective feedback on his or her performance based on the task analysis. Other extraneous comments typical of the trainer's coaching style were not limited. The participant then had the opportunity to review the video for up to 1 min following feedback for further analysis. No live modeling by the trainer was provided during this procedure. The participant then completed the lift two more times using this same process. Following three trials of the clean and jerk, the participant performed the snatch three times. No video feedback was given for the snatch while the snatch remained in baseline.

Once improvement was observed for the clean and jerk, the participant received the same instructions for the snatch, in addition to the clean and jerk. The participant received video feedback and a side-by-side comparison with an expert video modeling for both lifts. All lifts were recorded and scored based on the task analysis for each lift. The participant again received verbal positive and corrective feedback on his or her performance while viewing the video and had the opportunity to review the video for up to $1 \mathrm{~min}$ following the lift for analysis. Similarly to intervention on the first lift, the participant was asked to complete the snatch two more times. The intervention procedure for the clean and jerk continued while the second lift (snatch) was in intervention.

The procedure remained the same for all three participants; however, Annie began with intervention on the snatch before intervention on the clean and jerk.

Maintenance. Maintenance sessions were conducted for all of the participants. During maintenance sessions, baseline conditions were in effect and participants did not receive video 
feedback. Maintenance sessions were conducted at 1 week and 4 weeks for each participant. Rich participated in one additional maintenance session at 6 weeks due to dropping the bar and scoring below $50 \%$ on one of his 4 week maintenance lifts. In week 6 of maintenance Rich performed all 3 lifts to completion.

\section{Social Validity Measures}

A social validity questionnaire (Appendix E) was provided to the participants following their last intervention session. The questionnaire included: ratings of how much the participant enjoyed the video modeling and video feedback procedure, how intrusive the procedure was to typical practice, if the participant felt the procedure was helpful, the overall ease of use, and their preference for using video feedback in the future. The questionnaire also provided the opportunity for participants to include descriptive feedback of the procedure. Each question contained a rating scale from strongly disagree to strongly agree, which is displayed in Table 2 as a liker scale rating of 1 to 5 with 1 corresponding with strongly disagree to 5 for strongly agree. Question 7 of the social validity questionnaire asked the participant's overall opinion of the study on a 5 point scale $($ great $=5$, very bad $=1)$.

An additional social validity measure was taken by having a certified trainer who was not involved in the study, score and rate 1 baseline and 1 intervention lift for each participant. The coach was blind to which lifts were baseline versus intervention lifts. Videos of each lift were chosen from baseline and the last 4 lifts of intervention at random. The trainer first scored the selected lifts using the task analysis then rated the videos on their opinion of the participant's confidence, fluidity, safety and overall performance. The trainer indicated her opinion on a 5 point rating scale with 5 corresponding with strongly agree and 1 corresponding with strongly disagree. 


\section{Chapter Three:}

\section{Results}

Figure 1. and table 1. show the percent correct on the task analysis for the clean and jerk and snatch for each participant in baseline, intervention and follow up. Averages were taken based on the entire baseline for each participant and only the last 4 lifts of intervention. Only the last 4 lifts of intervention were included in the intervention average to reflect the overall acquisition the participant made in the course of intervention. During baseline, Annie averaged $37.2 \%$ of correct steps on the task analysis for clean and jerks, and $24 \%$ for the snatch. Following intervention, Annie scored an average of $78.5 \%$ on clean and jerks and $75 \%$ for the snatch. Annie participated in 1 and 4 week follow up sessions which she performed an average of $82.1 \%$ across 3 clean and jerks and $85.3 \%$ on 3 snatches in the 1 week follow up. In the 4-week follow up, she scored an average of $83 \%$ on 3 clean and jerks and $82 \%$ for 3 snatches.

During baseline, Rich scored an average of $78.75 \%$ of steps correct for clean and jerks, and $57.63 \%$ on the snatch task analysis. During intervention, Rich scored an average of $95 \%$ on clean and jerks and $89 \%$ for the snatch. Rich participated in 1, 4, and 6 week follow up sessions which he performed and average of $95 \%$ across 3 clean and jerks and $90.66 \%$ on 3 snatches in the 1 week follow up. In the 4 week follow up he scored an average of $91.66 \%$ on 3 clean and jerks and $83 \%$ for 2 snatches. Only two of the three snatches in Rich's 4 week follow up were included in the average as his second snatch during this session was dropped, and only scored $38 \%$ on the lift, which is not representative of his performance (see * on figure 1 ). Rich 
participated in a 6 week follow up in which he scored an average of $90 \%$ on 3 clean and jerks and $89 \%$ for 3 snatches.

In baseline, Fran averaged $60.18 \%$ of correct steps on the task analysis for clean and jerks, and $51.38 \%$ for the snatch. Following intervention, Fran scored an average of $86.75 \%$ on clean and jerks and $84.5 \%$ for the snatch. Fran also participated in 1 and 4 week follow up sessions which she performed and average of $87.33 \%$ across 3 clean and jerks and $81.33 \%$ on 3 snatches in the 1 week follow up. In the 4-week follow up, she scored an average of $81 \%$ on 3 clean and jerks and $81.33 \%$ for 3 snatches.

Overall, Annie improved an average of $41.3 \%$ on clean and jerk and $51 \%$ on snatch performance from baseline to the last four lifts of intervention. Rich improved performance an average of $16.25 \%$ on clean and jerk, and $31.37 \%$ on the snatch from baseline to the last four lifts of intervention. Fran's performance increased on an average of $26.57 \%$ on clean and jerk, and $33.12 \%$ on snatch from baseline to the last four lifts of intervention.

Results for social validity are displayed in Table 2. Participants rated all questions highly surrounding their satisfaction with his or her participation, results for both types of lift, the ease of use for the video application, and desire to use video feedback in the future. Annie, Rich and Fran scored the social validity surveys with an overall average of 4.9, 5 and 5 respectively.

Table 3 reflects the trainer's social validity scoring based on the task analysis. The trainer was blind to the phase of the study in which the lifts occurred and scored the lifts based on the task analysis. The primary researcher compared the trainer's rating of each lift from baseline to intervention. The blind scoring results for the clean and jerk reflected a $24 \%, 33 \%$, and $48 \%$ increase from baseline to intervention for Fran, Rich and Annie respectively, and a 24\%, 33\% and $48 \%$ increase for the snatch respectively. 
The trainer also rated the lifts on the participant's confidence, fluidity, safety, and overall correct performance for each lift. The rating was based on a 5 point scale with 1 representing strongly disagree to 5 representing strongly agree. All participants either maintained or improved in the trainer's opinion when ratings of the lifts were compared. Results from the trainer's rating can be found in Table 4. 


\section{Tables and Figures}

\section{Table 1}

Average Scores for Clean and Jerks and Snatches

\begin{tabular}{|c|c|c|c|c|c|c|}
\hline Lift & Participant & BL Avg. & $\begin{array}{l}\text { Intervention } \\
\text { Avg.^}\end{array}$ & $\begin{array}{l}\text { Week } 1 \\
\text { Follow up }\end{array}$ & $\begin{array}{l}\text { Week } 4 \\
\text { Follow Up }\end{array}$ & $\begin{array}{l}\text { Week } 6 \\
\text { Follow up }\end{array}$ \\
\hline \multirow{3}{*}{$\begin{array}{l}\text { Clean and } \\
\text { Jerk }\end{array}$} & Annie & 37 & 79 & 82 & 83 & $\mathrm{~N} / \mathrm{A}$ \\
\hline & Rich & 79 & 95 & 95 & 92 & 90 \\
\hline & Fran & 60 & 87 & 87 & 81 & $\mathrm{~N} / \mathrm{A}$ \\
\hline \multirow[b]{3}{*}{ Snatch } & Annie & 24 & 75 & 85 & 82 & N/A \\
\hline & Rich & 58 & 89 & 91 & $83 *$ & 89 \\
\hline & Fran & 51 & 85 & 81 & 81 & N/A \\
\hline
\end{tabular}

Notes. An * indicates only 2 lifts of 3 trails were scored during this session due to an incomplete lift. $\mathrm{A}^{\wedge}$ indicates that intervention average is the average of the last 4 data points of intervention. 


\section{Table 2}

Results from Participants' Social Validity Questionnaire

\begin{tabular}{|c|c|c|c|c|c|c|c|c|}
\hline & $\begin{array}{l}\text { I enjoyed } \\
\text { participating } \\
\text { in this study }\end{array}$ & $\begin{array}{l}\text { I am happy } \\
\text { with the } \\
\text { overall } \\
\text { results I } \\
\text { achieved }\end{array}$ & $\begin{array}{l}\text { The video } \\
\text { feedback } \\
\text { was helpful } \\
\text { in } \\
\text { improving } \\
\text { my clean } \\
\text { and jerk }\end{array}$ & $\begin{array}{l}\text { The video } \\
\text { feedback I } \\
\text { received was } \\
\text { helpful in } \\
\text { improving } \\
\text { my snatch }\end{array}$ & $\begin{array}{l}\text { The Coaches } \\
\text { Eye(C) } \\
\text { application } \\
\text { was easy use } \\
\text { and did not } \\
\text { disrupt my } \\
\text { workout }\end{array}$ & $\begin{array}{l}\text { I would like } \\
\text { to use video } \\
\text { feedback } \\
\text { more often } \\
\text { when I am } \\
\text { practicing } \\
\text { lifts/skills }\end{array}$ & $\begin{array}{l}\text { My } \\
\text { overall } \\
\text { opinion of } \\
\text { the study }\end{array}$ & $\begin{array}{l}\text { Avg. } \\
\text { Rating }\end{array}$ \\
\hline Annie & 5 & 5 & 5 & 5 & 5 & 4 & 5 & 4.9 \\
\hline Rich & 5 & 5 & 5 & 5 & 5 & 5 & 5 & 5 \\
\hline Fran & 5 & 5 & 5 & 5 & 5 & 5 & 5 & 5 \\
\hline
\end{tabular}

Notes. Participants noted on their questionnaires the intervention helped improve the lifts. One participant noted he or she liked being able to see a side-by-side comparison of their lift with the expert model. Participants noted that the intervention was easy and did not require more time he or she already planned for the workout. 
Table 3

Results from Trainer's Blind Scoring Social Validity

\begin{tabular}{|c|c|c|c|c|}
\hline \multirow{2}{*}{} & \multicolumn{2}{|c|}{ Snatch } & \multicolumn{2}{c|}{ Clean and Jerk } \\
\cline { 2 - 5 } & Baseline & Intervention & Baseline & Intervention \\
\hline Annie & $38 \%$ & $78 \%$ & $33 \%$ & $81 \%$ \\
\hline Rich & $72 \%$ & $94 \%$ & $67 \%$ & $100 \%$ \\
\hline Fran & $44 \%$ & $78 \%$ & $62 \%$ & $86 \%$ \\
\hline
\end{tabular}

Notes. Scores for each lift are based on the task analysis. Percentages in the table reflect the scoring of 1 individual lift. Lifts were selected at random from baseline and intervention. 


\section{Table 4}

Results from Trainer's Social Validity Rating

\begin{tabular}{|l|c|c|c|c|c|c|c|c|c|c|c|c|}
\hline & \multicolumn{9}{|c|}{ Snatch } & \multicolumn{6}{c|}{ Clean and Jerk } \\
\cline { 2 - 13 } & \multicolumn{2}{|c|}{ Annie } & \multicolumn{2}{|c|}{ Rich } & \multicolumn{2}{c|}{ Fran } & \multicolumn{2}{|c|}{ Annie } & \multicolumn{2}{c|}{ Rich } & \multicolumn{2}{c|}{ Fran } \\
\cline { 2 - 14 } & BL & I & BL & I & BL & I & BL & I & BL & I & BL & I \\
\hline $\begin{array}{l}\text { Participant } \\
\text { performed the } \\
\text { lift with } \\
\text { confidence }\end{array}$ & 1 & 4 & 4 & 4 & 2 & 4 & 1 & 5 & 5 & 5 & 2 & 4 \\
\hline $\begin{array}{l}\text { Participant } \\
\text { performed the } \\
\text { lift fluidly }\end{array}$ & 1 & 4 & 4 & 5 & 3 & 4 & 1 & 5 & 4 & 5 & 3 & 4 \\
\hline $\begin{array}{l}\text { Participant } \\
\text { performed the } \\
\text { lift safely }\end{array}$ & 2 & 4 & 4 & 4 & 4 & 4 & 3 & 5 & 4 & 5 & 4 & 4 \\
\hline $\begin{array}{l}\text { Participant } \\
\text { performed the } \\
\text { lift correctly }\end{array}$ & 2 & 4 & 4 & 5 & 3 & 4 & 2 & 4 & 4 & 5 & 3 & 4 \\
\hline
\end{tabular}

Notes. Ratings are based on a 5 point likert scale from 1 (strongly disagree) to 5 (strongly agree) 

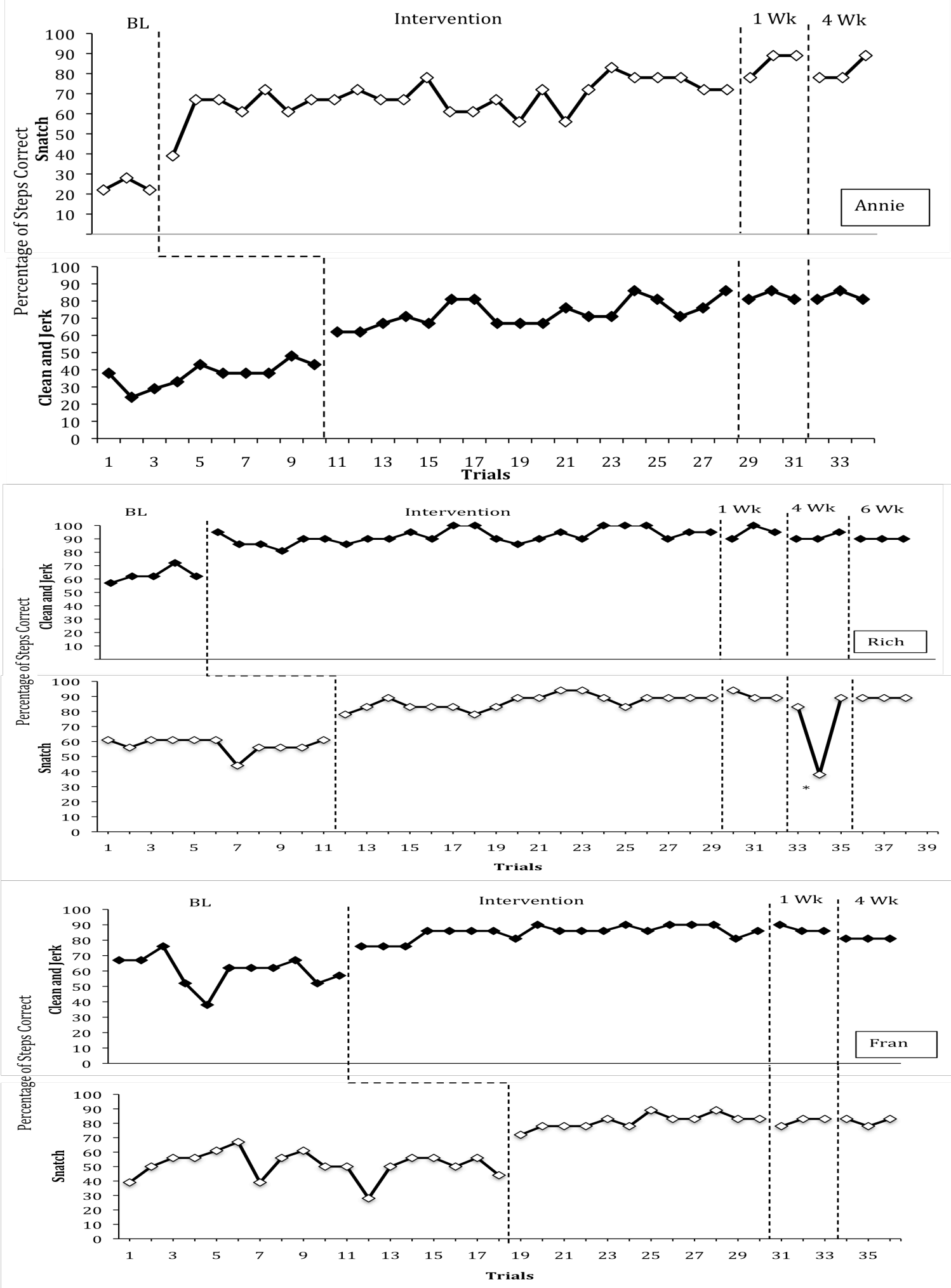

Figure 1. Percentage of Correct Steps Displayed Across Behaviors. Percentage correct of steps on the task analysis for each lift (clean and jerk and snatch) across baseline, intervention and follow up for each participant showing multiple baseline across behaviors. * next to a data point indicates a dropped lift. 


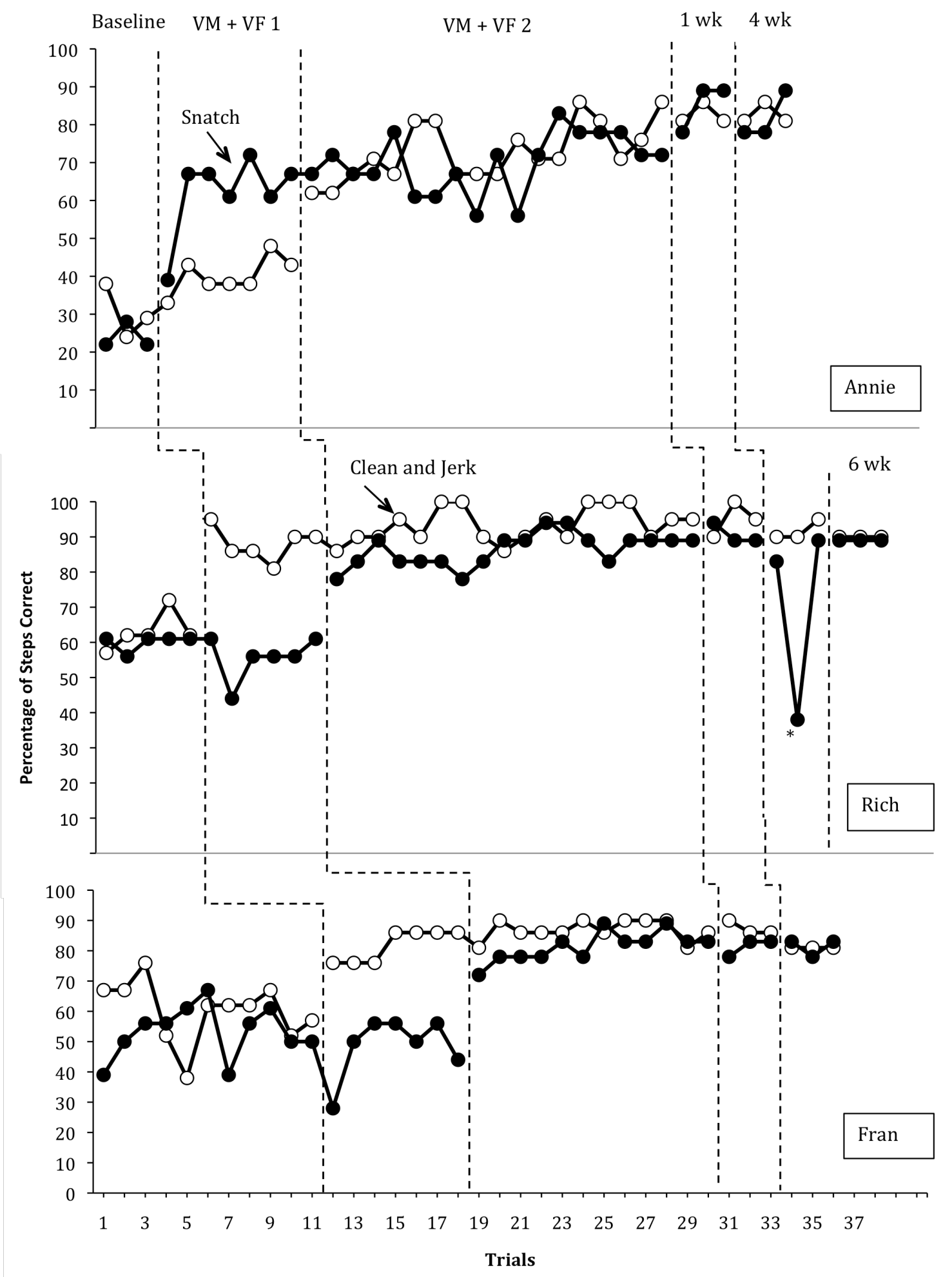

Figure 2. Percentage of Correct Steps Displayed Across Participants. Percentage correct of steps on the task analysis for each lift (clean and jerk and snatch) across baseline, intervention and follow up for each participant showing multiple baseline across participants. 


\section{Chapter Four:}

\section{Discussion}

The current study evaluated the effects of video modeling and video feedback on two Olympic weightlifting lifts (clean and jerk and snatch) to improve performance based on a task analysis for each lift. All three participants were identified by trainers as needing improvement on their lifts and all three participants were motivated to work on improving their technique. Each of the participants began the study with a different length of experience and different levels of performance. Once intervention began with video modeling and video feedback, all three participants showed immediate improvement in each of their lifts from baseline. For Rich and Fran the improvement observed from baseline to intervention stabilized within a range of 15 percentage points all remaining above baseline levels. Annie improved 45 percentage points from baseline to her second intervention point in the snatch, and a 19 percentage points from baseline to intervention on the clean and jerk. The change from baseline to intervention on Annie's lifts resulted in over 200\% performance improvement from baseline on her snatch and nearly $100 \%$ increase from baseline to intervention on her clean and jerk. Annie's lifts continued to improve overall throughout the study, which may be partially attributed to her limited experience with the lifts.

Annie began intervention with the snatch followed by intervention on the clean and jerk, due to a concern that repetitive lifting with lack of sufficient technique might result in injury without immediate intervention. The snatch is typically the more difficult lift to perform due to the fluidity of the motion. Additionally Annie's baseline levels appeared more stable than that of 
her clean and jerk warranting intervention. The intervention was successful in improving performance on the lifts and likely reducing the injury potential for the three participants. Some of the errors frequently seen in the videos from the participants were over extension of the arms on the catch for the snatch, which placed stress on the rotator cuff; and pulling the bar up to the hips while standing up from the ground position, this error placed more pressure on the lower back and recruited major muscle groups to lift the heavy weight rather than using upward force (momentum) from an explosion of the hips. Finally, participants frequently caught the bar with their body weight shifted over their toes, which placed more pressure on the knees and strained the ankles. These errors are only some of the performance errors seen throughout the study. All of these errors can be seen in earlier videos, and most appear to be corrected in later videos following intervention.

The evaluation of video modeling and feedback as a stand alone intervention has not been evaluated in the area of Olympic weightlifting prior to this study; however, the results partially replicate the findings from the Boyer et al. (2009) video modeling and video feedback study on gymnastics skills. The intervention aided with skill acquisition, but was not sufficient to achieve $100 \%$ acquisition of the skills for the majority of trials. It was not expected that technique for each lift would improve to $100 \%$ accuracy for each trial due to the complexity of the lifts; however, it was expected that participants would achieve 80 to $100 \%$ accuracy with the video intervention. All of the participants achieved at least $80 \%$ accuracy throughout intervention. This study may suggest that video modeling and video feedback is a valuable procedure to incorporate into training for improving foundational skills in Olympic weightlifting.

All of the participants rated the study and results highly on the social validity questionnaires. The participants included comments indicating the intervention helped improve 
his or her form. One participant commented on the convenience of the intervention stating, "I liked the flexibility with my schedule," and "no extra time (was) required" for the intervention. The intervention was easy to implement and addressed some of the limitations of other studies involving video feedback, which indicate that video feedback was time consuming. The feedback intervention in the current study was immediate and took no more than 1 minute to provide following the completion of each lift, thus, eliminating post session feedback that has been reported to take up to $45 \mathrm{~min}$.

Other anecdotes supporting the external validity of this intervention came from other members of the gym where the study took place. At times during the study other members observed the participants and provided positive comments on their performance indicating they had made improvement in their technique. The coaches assisting with the study did not fill out formal social validity questionnaires, but commented on the improvement for all 3 of the participants. One coach referred to Annie's improvements as, "night and day."

This study expanded the current body of literature on video modeling and feedback as an acquisition tool in athletics, specifically for improving form. The present study included 3 participants with different skill levels, and immediate improvement could be seen upon the implementation of intervention regardless of experience. Though the study only included 3 participants, 6 replications of the effect of the video modeling and video feedback intervention was displayed in the data. While this study demonstrated behavior acquisition in intervention, there were some limitations.

One limitation to this study was that the task analysis for scoring did not take into account improvement in the steps for completing each lift. For example, a common error for the participants was pulling up on the bar (bending their elbows) prior to extending their hips, which 
reduces the amount of upward force (power) to drive the bar upward without using major muscle groups in the arms or back; however, in Annie's case the bend in her elbows in baseline and early intervention was far more drastic than later in intervention. Regardless of the severity of the bend in her elbows, the step was marked incorrect even though she had made vast improvement on this step. Future research may include a scale to operationally define degrees of improvement. Additionally, future research should attempt to replicate the findings from this study with more participants to build support for the intervention. Future research may also explore different experience levels for the participant to target perfecting lifts, or other athletic skills completely. The present study only evaluated form while using the same weight range determined prior to baseline. Future research in the area of Olympic weightlifting and video feedback may also seek to evaluate the effect of improvement on the participant's ability to increase his or her 1 rep max, as the typical goal in Olympic weightlifting is the ability to increase the amount of weight one can lift with perfect form. Future studies may also evaluate the effects of peer training. Video modeling by an expert model and video feedback should be evaluated when delivered by another member of the gym (not a trainer) with the aid of a task analysis during skills training to evaluate if the intervention is effective in the absence of a trainer.

To conclude, the study evaluated video modeling and video feedback on technique for two Olympic weightlifting lifts for 3 participants with different levels of experience. All 3 participants improved their form following intervention faster than standard coaching by a minimum of 17 percentage points for each lift. The participants enjoyed the study, looked forward to receiving video feedback, and felt they benefited from the intervention. The present study was the first to evaluate behavioral coaching tools in Olympic weightlifting, and addressed some of the limitations seen in previous studies involving video feedback. 


\section{References}

Allison, M.G., \& Ayllon, T. (1980) Behavioral coaching in the development of skills in football, gymnastics, and tennis. Journal of Applied Behavior Analysis, 13, 297-314.

Benitez-Santiago, A. S., Miltenberger, R.G. (2011) Using video feedback to improve martial-arts performance. (Unpublished master's thesis). University of South Florida, Tampa.

Boyer, E., Miltenberger, R. G., Batsche, C., \& Fogel, V. (2009). Video modeling by experts with video feedback to enhance gymnastics skills. Journal of Applied Behavior Analysis, 42, 855-860.

Dowrick, P. W. (1991) Practical guide to using video in the behavioral sciences. New York, NY; John Wiley \& Sons, Inc.

Fitterling, J. M., \& Ayllon, T., (1983). Behavioral coaching in classical ballet: Enhancing skill development. Behavior Modification, 7, 345-368.

Folger, T. (2006) The greatest workout known to man. Men's Health , 21(7), p126-128.

Harle, S. K., \& Vickers, J. N. (2001). Training quiet eye improves accuracy in the basketball free- throw. The Sport Psychologist, 15, 289-305.

Hazen, A., Johnstone, C., Martin, G. L., \& Srikameswaran, S. (1990). A videotaping feedback package for improving skills of youth competitive swimmers. The Sport Psychologist, 4, 213-227.

Kladopolous, C. N., \& McComas, J. J. (2001). The effects of form training of foul-shooting performance in members of a women's collegiate basketball team. Journal of Applied Behavior Analysis, 34, 329-332.

McKenzie, T. L., \& Rushall, B. S. (1974) Effects of self-recording on attendance and performance in a competitive swimming training environment. Journal of Applied Behavior Analysis, 7, 199-206.

Rothstein, A. L. \& Arnold, R. K. (1976). Bridging the gap: Application of research on videotaped feedback and bowling. Motor Skills: Theory into Practice, 1, 35-62.

Shapiro, E. S., \& Shapiro, S. (1985) Behavioral coaching in the development of skills in track. Behavior Modification, 9, 211-224. 
Smith, S.L. \& Ward, P. (2006) Behavioral interventions to improve performance in collegiate football. Journal of Applied Behavior Analysis, 39, 385-391.

Stokes, J. V., Luiselli, J. K., Reed, D. D., and Fleming R. K. (2010). Behavioral coaching to improve offensive line pass-blocking skills of high school football athletes. Journal of Applied Behavior Analysis, 43, 463-472.

Stone, M.H., Fry, A.C., Ritchie, M., Stoessel-Ross, L., Marsit, J.L. (1994) Injury potential and safety aspects of weightlifting movements. Strength and Conditioning Journal, 16 (3), 1521.

Sullivan, D., (n.d) A brief history of CrossFit. VPXSports. Retrieved April 6, 2013. From http://www.vpxsports.com/article-detail/industry-news/a-brief-history-of-CrossFit.

Wolko, K. L., Hrycaiko, D. W., \& Martin, G. L. (1993). A comparison of two self-management packages to standard coaching for improving practice performance of gymnasts. Behavior Modification, 17, 209-223.

Zeigler, S. G. (1994) The effects of attentional shift on the execution of soccer skills: A preliminary investigation. Journal of Applied Behavior Analysis, 27, 545-552. 
Appendices 


\section{Appendix A: Inclusion Criteria}

\section{INCLUSION CRITERIA}

This area specifies the criteria that will be considered when determining whether or not the participant will be admitted into the study:

- I am in good physical health (PAR-Q)

- I am at no/low risk for health problems or injuries (PAR-Q)

- I have no more than one year experience in Olympic lifting and/or CrossFit combined

- I am motivated to improve my lifting form

- I have plans to participate in a minimum of 3 workouts per week

- I have completed CrossFit "on-ramp" or "fundamentals" course prior to participating in the study for safety purposes.

- I plan to continue this study until criteria have been met 


\section{Appendix B: Physical Activity Readiness Questionnaire (PAR-Q)}

\section{PAR-Q}

Regular physical activity is fun and healthy, and increasingly more people are starting to become more active every day. Being more active is very safe for most people. However, some people should check with their doctor before they start becoming much more physically active.

If you are planning to become much more physically active than you are now, start by answering the seven questions in the box below. If you are between the ages of 15 and 69, the PAR-Q will tell you if you should check with your doctor before you start. If you are over 69 years of age, and you are not used to being very active, check with your doctor.

Common sense is your best guide when you answer these questions. Please read the questions carefully and answer each one honestly: answer YES or NO.

1. Has your doctor ever said that you have a heart condition and that you should only do physical activity recommended by a doctor?

2. Do you feel pain in your chest when you do physical activity?

3. In the past month, have you had chest pain when you were not doing physical activity?

4. Do you lose your balance because of dizziness or do you ever lose consciousness?

5. Do you have a bone or joint problem (for example, back, knee or hip) that could be made worse by a change in your physical activity?

6. Is your doctor currently prescribing drugs (for example, water pills) for your blood pressure or heart condition?

7. Do you know of any other reason why you should not do physical activity? 
Appendix C: Task Analysis/Data Collection Sheet: Clean and Jerk

Participant (initials only):

$65 \%$ of one rep max:

lbs

Phase:___ Session \#:

Weight on bar:

$\underline{\mathrm{lbs}}$

Coach's initials:

Clean and Jerk Checklist

\begin{tabular}{|c|c|c|c|}
\hline Steps & Component & Component Descriptions & $\begin{array}{l}\text { Trial } \\
1\end{array}$ \\
\hline 1 & Ground & $\begin{array}{l}\text { Hands in close grip (about shoulder width apart) } \\
\text { with arms straight }\end{array}$ & \\
\hline 2 & & Shoulders back with shoulder blades engaged & \\
\hline 3 & & $\begin{array}{l}\text { Eye gaze forward with chin level or slightly elevated } \\
\text { chin }\end{array}$ & \\
\hline 4 & & Feet in jump position, about shoulder width apart & \\
\hline 5 & Pull One & Lead up with chest (does not round back) & \\
\hline 6 & & Bar remains close/drags past shins and knees & \\
\hline 7 & & Bar drags up thighs & \\
\hline 8 & Pull Two & Open Hips, move feet to landing position & \\
\hline 9 & Pull Three & Elbows bend clearly after hip extension & \\
\hline 10 & & $\begin{array}{l}\text { Bar remains close to body on pull (forearms angled } \\
\text { down less than } 90 \text { degrees with body) }\end{array}$ & \\
\hline 11 & Catch & $\begin{array}{l}\text { Bar is caught in full squat with hip crease below the } \\
\text { knee }\end{array}$ & \\
\hline 12 & & Elbows rotate under and in front of bar & \\
\hline 13 & Stand & $\begin{array}{l}\text { Center bodyweight on heels (doesn't bend } \\
\text { forward/stand on toes) }\end{array}$ & \\
\hline 14 & & Lead with chest (engaged hamstrings) to stand & \\
\hline 15 & & $\begin{array}{l}\text { Feet come together to jumping position from } \\
\text { landing position once standing }\end{array}$ & \\
\hline 16 & Dip & Knees bend slightly & \\
\hline 17 & Drive & Open hips (hip extension) & \\
\hline 18 & Dip & Drop under bar while pressing bar above head. & \\
\hline 19 & & Feet land in split with arms fully extended overhead & \\
\hline 20 & Stand & Push off forward foot to begin stand & \\
\hline 21 & & $\begin{array}{l}\text { Bring feet to shoulder width apart (while bar is fully } \\
\text { extended) }\end{array}$ & \\
\hline
\end{tabular}




\section{Appendix D: Task Analysis/Data Collection Sheet: Snatch}

Participant (initials only):

$65 \%$ of one rep max:

lbs
Phase: ___ Session \#:

Weight on bar: ___

Coach's initials:

Snatch Checklist

\begin{tabular}{|c|c|c|c|}
\hline Steps & Component & Component Descriptions & $\begin{array}{l}\text { Trial } \\
1\end{array}$ \\
\hline 1 & Ground & Hands in wide grip with arms in full extension & \\
\hline 2 & & Shoulders back with shoulder blades engaged & \\
\hline 3 & & $\begin{array}{l}\text { Eye gaze forward with chin level or slightly elevated } \\
\text { chin }\end{array}$ & \\
\hline 4 & & Feet in jump position, about shoulder width apart & \\
\hline 5 & Pull one & Chest up, back concave or straight & \\
\hline 6 & & Bar remains close/drags past shins and knees & \\
\hline 7 & Pull two & Knees push back/sweep bar back against thighs & \\
\hline 8 & Pull three & Open Hips, move feet to landing position (squat stance) & \\
\hline 9 & & Elbows bend clearly after hip extension & \\
\hline 10 & & Bar remains close to body on pull & \\
\hline 11 & & Body drops below the bar at max pull height & \\
\hline 12 & Catch & Hip crease below the knee & \\
\hline 13 & & $\begin{array}{l}\text { Arms locked out underneath bar (without pushing the } \\
\text { bar overhead) }\end{array}$ & \\
\hline 14 & & $\begin{array}{l}\text { Active shoulders, shoulders engaged with underarms } \\
\text { facing forward (no external rotation) }\end{array}$ & \\
\hline 15 & & $\begin{array}{l}\text { Center bodyweight on heels (don't bend forward/catch } \\
\text { on toes) }\end{array}$ & \\
\hline 16 & Stand & Lead with chest (engaged hamstrings) & \\
\hline 17 & & $\begin{array}{l}\text { Maintain the bar in frontal plane. (Bar remains in the } \\
\text { middle of body plane) }\end{array}$ & \\
\hline 18 & & $\begin{array}{l}\text { Return feet to jumping position, (feet come together hip } \\
\text { width apart) }\end{array}$ & \\
\hline
\end{tabular}




\section{Appendix E: Social Validity Questionnaire}

Please rate the following:

\section{Social Validity Questionnaire}

1. I enjoyed participating in this study:

$\square$ Strongly Disagree $\quad \square$ Disagree $\quad \square$ No Opinion $\quad \square$ Agree $\quad \square$ Strongly Agree Why:

2. I am happy with the overall results I achieved as part of the study:

$\square$ Strongly Disagree $\quad \square$ Disagree $\quad \square$ No Opinion $\quad \square$ Agree $\quad \square$ Strongly Agree Why:

3. The video feedback I received was helpful in improving my form/technique for the clean and jerk:

\section{$\square$ Strongly Disagree $\quad \square$ Disagree $\quad \square$ No Opinion $\quad \square$ Agree $\quad \square$ Strongly Agree} Why:

4. The video feedback I received was helpful in improving my form/technique for the snatch:

$\square$ Strongly Disagree $\quad \square$ Disagree $\quad \square$ No Opinion $\quad \square$ Agree $\quad \square$ Strongly Agree Why:

5. The Coaches Eye $\bigcirc$ application was easy enough to use that it did not disrupt my workout:

$\square$ Strongly Disagree $\quad \square$ Disagree $\quad \square$ No Opinion $\quad \square$ Agree $\quad \square$ Strongly Agree Why:

6. I would like trainers/coaches to use video feedback more often when I am practicing lifts/skills: 


\section{$\square$ Strongly Disagree $\quad \square$ Disagree $\quad \square$ No Opinion $\quad \square$ Agree $\quad \square$ Strongly Agree}

Why:

7. My overall opinion of the study:

$\square$ Great $\quad \square$ Good $\quad \square$ Okay $\quad \square$ Bad $\quad \square$ Very Bad

Why:

8. What did you like MOST about the study?

9. What did you like LEAST about the study?

10. Further Recommendations:

Thank you for your time! :) 


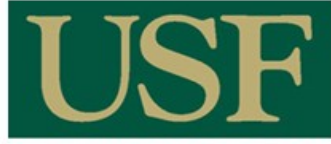

UNIVERSITY OF

SOUTH FLORIDA
RESEARCH INTEGRITY AND COMPLIANCE

Institutional Review Boards, FWA No. 00001669

12901 Bruce B. Downs Blvd., MDC035 • Tampa, FL 33612-4799

(813) 974.5638 • FAX(813)974-7091

$2 / 28 / 2014$

THIS LETTER SUPERSEDES THE LETTER DATED

$2 / 17 / 2014$

Danah Mulqueen, BCaBA

ABA-Applied Behavior Analysis

4202 East Fowler Ave.

Tampa, FL 33620

\section{RE: Full Board Approval for Initial Review}

IRB\# Pro00015918

Title: Using Video Modeling and Video Feedback to Improve Olympic Weightlifting

\section{Study Approval Period: 2/14/2014 to 2/14/2015}

Dear Ms. Mulqueen:

On 2/14/2014, the Institutional Review Board (IRB) reviewed and APPROVED the above application and all documents outlined below.

\section{Approved Item(s):}

Protocol Document(s):

Thesis Proposal

\section{Consent/Assent Document(s)*:}

15918 Adult icf ver 1 1.7.14.docx.pdf

*Please use only the official IRB stamped informed consent/assent document(s) found under the "Attachments" tab. Please note, these consent/assent document(s) are only valid during the approval period indicated at the top of the form(s).

As the principal investigator of this study, it is your responsibility to conduct this study in accordance with IRB policies and procedures and as approved by the IRB. Any changes to the approved research must be submitted to the IRB for review and approval by an amendment. 
We appreciate your dedication to the ethical conduct of human subject research at the University of South Florida and your continued commitment to human research protections. If you have any questions regarding this matter, please call 813-974-5638.

Sincerely,

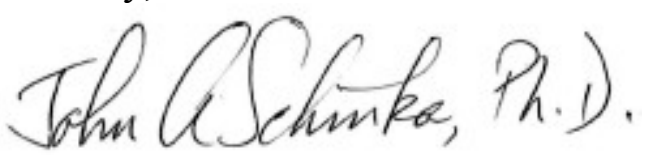

John Schinka, Ph.D.,

Chairperson USF Institutional

Review Board 